\title{
PREVALENCE OF INTESTINAL PROTOZOA AMONG PATIENTS WITH IN- FLAMMATORY BOWEL DISEASE AND IRRITABLE BOWEL SYNDROME
} By

SAMIRA METWALLY MOHAMMAD', HOWAYDA S. F. MOAWAD', And MAGDA M. SHERIF²

Departments of Medical Parasitology ${ }^{1}$ and Internal Medicine ${ }^{2}$, Faculty of Medicine, Zagazig University, Egypt ( ${ }^{*}$ Correspondence: samirametwally1971@gmail.com)

\section{Abstract}

Intestinal parasites have a great influence on patients with gastro-intestinal disorders especially those with inflammatory bowel disease (IBD) and irritable bowel syndrome (IBS). This study detected the difference in prevalence of intestinal protozoa among these two groups of patients and evaluated the injury degrees caused by protozoa in gastrointestinal tract (GIT) by measuring the fecal calprotectin (FC) level. This study was done on 219 patients; 101 were IBD patients and 118 were IBS cases attended to the gastroenterology clinics, Zagazig University Hospitals in the period from May 2017 till May 2018 with gastrointestinal symptoms. Stool samples were taken. Microscopic examination for direct wet preparation using $0.9 \%$ of $\mathrm{NaCl}$ and $1 \%$ of Lugols iodine for each stool specimen was done then confirmed by formol ether sedimentation technique. Fecal smears from sediments of the concentrated samples were stained with modified Ziehl-Neelsen and Trichrome stains. Special ELISA kit was used for calprotectin (FC) fecal detection. Blood sample was taken from each case in EDTA tube for detection of total white blood count, neutrophil percentage, and the hemoglobin content.

Out of 219 stool samples, 84 were positive for intestinal protozoa (38.4\%); 58(57.4\%) of them were patients with IBD \& 26 (22\%) were patients with IBS. Entamoeba histolytica/dispar, Giardia lamblia, Blastocystis hominis, Cryptosporidium parvum and Cyclospora cayetanensis are the protozoa which were found among the positive cases. Prevalence among IBD was 27(27\%), 14(14\%), 10(10\%), 6(6\%) and $1(1 \%)$ respectively while among IBS were $10(8 \%), 6(5 \%), 7(6 \%), 2(2 \%)$ and $1(1 \%)$ respectively. High rates of E. histolyticaldispar (27\%), G. lamblia (14\%), and B. hominis (10\%) were among IBD patients as compared with IBS patients $(8 \%, 5 \%, 6 \%), \mathrm{P}<0.05$. Mean fecal calprotectin levels $\geq 50 \mathrm{ng} /$ $\mathrm{ml}$ was considered positive and detected in 15 cases $(40.5 \%)$ for E. histolytica, followed by 4(20\%) for G. lamblia, 3(17.6\%) for B. hominis and 1(14\%) for C. parvum; meanwhile FC level was negative for $C$. cayetanensis. There was significant correlation $\mathrm{P}<0.05$ among $\mathrm{FC}$, protozoan infections, total WBCs count and neutrophil\%.

Keywords: Patients, IBD, IBS, prevalence, Intestinal protozoa, ELISA, Faecal calprotectin.

\section{Introduction}

Gastrointestinal tract (GIT) is an important system in human body affected by many diseases as inflammatory bowel disease (Kaser et al, 2010), and irritable bowel syndrome with symptomatic confusion (Fengming and Jianbing, 2014). IBD is a chronic autoimmune inflammatory disease characterized by attacks of relapse and remission, with two subtypes ulcerative colitis (UC) and Crohn's disease (CD), and different signs and symptoms (Ponder and Long, 2013). Crohn's disease can affect any part from mouth to anus (Lennard-Jones, 1989), but the ulcerative colitis affects the rectum and colon mucosa causing typical ulcers (Parray et al, 2012).

At turn of the $21^{\text {st }}$ century, inflammatory bowel disease has become a global disease with accelerating incidence in newly industrialized countries whose societies have become more westernized. Although incidence is stabilizing in western countries, burden remains high as prevalence surpasses $0.3 \%$ (Ng et al, 2018). Helminthes high rate were in early childhood in developing countries might protect them against IBD by stimulation and modification of the immune responses (Adisakwattana et al, 2013).

The abnormal immunological response is due to the interaction between environmental and genetic agents causing in intestinal inflammation (Baumgart and Carding, 2007). A significant environmental factor in occurrence of IBD is the compositional changes in the intestinal microbiota. If these changes 
are harmful, they can produce an improper immune response which leads to intestinal epithelial damage and loss of its integrity (Maloy and, Powrie, 2011). Also, animal proteins may correlate with increased incidence of IBD and relapses (Andersen et al, 2012). The characteristic symptoms of IBD are abdominal pain, diarrhea, rectal bleeding, and weight loss, always with anemia (Wang et al, 2012).

Irritable bowel syndrome (IBS) is a GIT functional disorder without underlying lesion evidence, manifested by abdominal discomfort, bloating and changed bowel habits. It is highly prevalent and with unknown exact causes (Wilson et al, 2004). It's been linked to oversensitive gut nerves, stress, and a family history of IBS (Borgaonkar et $a l$, 2006). There are variable triggers for it, which may include certain hormones, medications, foods or an acute gastroenteritis episode (Longstreth et al, 2006).

The global prevalence of IBS is nearly $12 \%$ (Mertz, 2003). It is higher in industrialized countries and lower in developing ones (Gwee, 2005). Abdominal pain and diarrhea are common symptoms between patients with IBD and IBS. Colonoscopy is needed to rule out IBD, as negative endoscopy finding diagnose IBS (Hammood et al, 2016).

Amoebiasis is a protozoan infection caused by E. histolytica and affects nearly $10 \%$ of world's population (Lehmann et al, 2015). It is more prevalent in developing countries (Lau et al, 2013). Its symptoms can overlap with those of the inflammatory bowel disease causing difficulty in diagnosis and treatment of IBD (Hansen and Lund 1998). The risk of opportunistic infection with amebias is was higher in IBD patients due to the wide use of immunosuppressive drugs and corticosteroids treatment (Babić et al, 2016).

The occurrence of post-infectious IBS (PI-IBS) subsequent to infectious gastroenteritis ranges from $4 \%$ to $31 \%$, with an average incidence of $10 \%$ (Thabane et al, 2007). Different parasites as E. histolytica, B. hominis, Giardia spp., and Trichinella spp. are implicated agents in the development of PIIBS. In a historical cohort study of G. lamblia infected patients, prevalence of IBS was $46.1 \%$ as long as 3 years after exposure, compared with the controls 14\% (Wensaas et al, 2012). The PI-IBS following G. lamblia infection is also linked with an elevated duodenal mucosal cholecystokinin (CCK) (Dizdar et al, 2010).

Blastocystis hominis is one of the most widespread intestinal protozoa in developing and developed nations (Fletcher et al, 2012), usually in patients with diarrhea predominant IBS (Cekin et al, 2012). Its potential role in the development of IBS was suggested due to its penetration of mucosal layer (Stark et al, 2007), present in $67 \%$ of the IBS patients and this could be a serious diagnostic problem for IBS (Dogruman et al, 2010).

Cryptosporidium is transmitted via oocysts ingestion with contaminated food and/or water but, usually a self-limiting disease in immunocompetent patients (Griffiths, 1998). In patients with acquired immunodeficiency syndrome and transplant recipients, it involves as one of the most important opportunistic infections (Wolska-Kusnierz et al, 2007). Due to the increasing use of immunosuppressive drugs, IBD patients are more exposed to opportunistic infections. In the absence of adequate stool studies, these patients could be misdiagnosed and treated as a relapse. Cryptosporidium was associated with relapses in adult IBD patients (Vadlamudi et al, 2013), with the beginning of gastrointestinal symptoms after an acute cryptosporidiosis in spite of recovery and parasite disposal (Engsbro et al, 2014). Symptoms following $C$. parvum infection are the same as those of IBS patients indicating that possibility parasite causing PI-IBS (Jadallah et al, 2017).

Cyclospora cayetanensis is one of protozoa parasites causing diarrhea in developing countries (Eberhard et al, 1999), and foodborne disease in industrial countries (Mansfield and Gajadha, 2004) and travelers' diarrhea back from developing nations (Dre- 
naggi et al, 1998). In contrast to Cryptosporidium,which are infectious after excretion, Cyclospora cayetanensis speculate in soil before becoming infectious, by consumption of contaminated food and/or water. In immunocompetent hosts, self-limiting diarrhea is common with asymptomatic infections but may be fatal in children and AIDS patients (Shields and Olson, 2003). Microscopically, Cyclospora and Cryptosporidium are similar but Cyclospora oocysts are twice larger (Varea et al, 1998).

Fecal calprotectin (FC) is an antibody produced by neutrophil white blood cell during its challenge with the pathogens which cause IBD. It is a neutrophil cytoplasmic calcium-binding protein (Quail et al, 2009). It is also present in monocytes and early macrophage stage, response to local inflammation, degranulation when occurs in the intestinal lumen (Foell et al, 2009). FC is diagnosed serologic by ELISA, a level >50ng/ $\mathrm{ml}$ in severe GIT damage indicating endoscopic intervention (Kopylov et al, 2016). Also, it is detected in stool to differentiate between IBD and other non-inflammatory illness, as well as an accurate indicator for disease activity and follow-up (Sherwood, 2012). A negative result of this non-invasive diagnostic test is probably a true negative safely exclude IBD in children with chronic GIT symptoms (Holtman et al, 2016). Delay in diagnosing IBD leads to subsequent delay in proper medication causing many complications as irreversible growth failure, anemia and late sexual maturity (Kim and Ferry, 2004).

This study aimed to determine the prevalence of intestinal protozoa in IBD patients and IBS ones and to evaluate the injury degrees caused by these protozoa on the gastrointestinal tract by measuring fecal calprotectin (FC) level.

\section{Material and Methods}

Study design: The study was done from May 2017 to May 2018 on 219 patients (116 males \& 103 females), 101 IBD patients and 118 IBS ones, attended Gastroenterology
Clinics, Zagazig University Hospitals with GIT suggestive complications.

Ethical aspects: The Ethics Committee of Faculty of Medicine, Zagazig University was considered and, written consents were taken from patients whom were informed by the purpose and procedures of this study.

Stool samples were collected from patients and subjected to: a- Macroscopic examination for stool consistency, odor, color, and blood or mucous, and b- Microscopic examination of fecal specimens by direct smear and Lugol's iodine followed by formol-ether sedimentation (Cheesbrough, 2009). Also, modified Ziehl-Neelsen (Adegbola et al, 1994) and trichrome stains (Cheesbrough, 1987) were used.

Quantitative detection of fecal calprotectin by ELISA (Epitope Diagnostic Inc. Co, USA): The sandwich ELISA was used with two particular antibodies fixed to various human calprotectin epitopes.According to the manufacturer instructions, the standards, controls and specimens of patients were added to the microtiter plate wells which were coated with calprotectin antibodies, incubation of the plat for a short period followed by washing. Human calprotectin specific monoclonal antibody was conjugated to the horseradish peroxidase (HRP) enzyme which was added to all wells. A sandwich was made following a second incubation period and it consisted of a solid phase antibody, human calprotectin and a horseradish peroxidase conjugated monoclonal antibody. After that, washing was done to eliminate the buffer matrix and the unbound monoclonal antibodies. Subsequently, the substrate solution was added and incubated in a timed reaction. The immune-complex was measured by the spectrophotometric microplate reader. The immune complex enzymatic activity was directly proportional to the quantity of human calprotectin in the examined sample.

A standard curve was performed with the assessment of the FC concentration in the samples from this curve. FC below 50ng/ml 
was considered a negative result.

Venous blood from every patient was taken into an EDTA tube. Samples were used to evaluate hemoglobin content $(\mathrm{gm} / \mathrm{dl})$, total leucocytic count and neutrophils\%.

Statistical analysis: Data were analyzed by SPSS Version 17. Values were expressed as percentages. Chi-square test was used to study the variances between the studied parameters. Hemoglobin content and total leucocytic count were given as mean \pm standard deviation (SD) and analyzed using student T-test. Significance was at P- value $<0.05$.

\section{Results}

The results are given in tables $(1,2, \& 3)$ and figures $(1 \& 2)$

Table 1: Demographic data and parasitosis in IBD and IBS patients

\begin{tabular}{|c|c|c|c|c|c|}
\hline Variables & IBD & IBS & Total & $X^{2}$ test & $\mathrm{P}$-value \\
\hline Sex: Male & $61(60 \%)$ & $55(46.6 \%)$ & $116(53 \%)$ & 4.152 & $0.042 *$ \\
\hline Female & $40(40 \%)$ & $63(53.4 \%)$ & $103(47 \%)$ & & \\
\hline Ages: $15-35 y$ & $48(47.5 \%)$ & $39(33 \%)$ & $87(40 \%)$ & & \\
\hline $36-50 y$ & $31(30.7 \%)$ & $52(44 \%)$ & $83(38 \%)$ & 5.468 & 0.065 \\
\hline$>50 y$ & $22(21.8 \%)$ & $27(23 \%)$ & $49(22 \%)$ & & \\
\hline Residence: Rural & 59 & 67 & 126 & & \\
\hline Urban & 42 & 51 & 93 & 0.059 & 0.807 \\
\hline Parasitiosis: +ve & $58(57.4 \%)$ & $26(22 \%)$ & $84(38.4 \%)$ & 28.83 & $0.00001 *$ \\
\hline -ve & $43(42.6 \%)$ & $92(78 \%)$ & $135(61.6 \%)$ & & \\
\hline Total & 101 & 118 & 219 & & \\
\hline
\end{tabular}

A total of 116 (53\%) were males and 103 $(47 \%)$ females. Males showed highest IBD (60\%), females showed highest IBS (53.4\%) with a significant difference. As to ages, IBD affected age group was from 15 to 35 years $(47.5 \%)$, while the IBS affected age group was from 36 to 50 years (44\%) without significant difference. Most of IBD and IBS cases were from rural areas (126) cases without significant difference.

Table 2: Fecal calprotectin antibody levels among parasitic infected patients:

\begin{tabular}{|c|c|c|c|c|c|}
\hline \multirow[t]{2}{*}{ Parasite } & \multicolumn{2}{|c|}{ Fecal calprotectin antibody } & \multirow[b]{2}{*}{ Total } & \multirow[t]{2}{*}{$X^{2}$ - test } & \multirow[t]{2}{*}{$\mathrm{P}$ - value } \\
\hline & $+\mathrm{ve}$ & $-\mathrm{ve}$ & & & \\
\hline Entamoeba histolytica/dispar & $15(40.5 \%)$ & $22(59.5 \%)$ & $37(40 \%)$ & \multirow{6}{*}{5.77} & \multirow{6}{*}{0.217} \\
\hline Blastocystis hominis & $3(17.6 \%)$ & $14(82.4 \%)$ & $17(20.2 \%)$ & & \\
\hline Giardia lamblia & $4(20 \%)$ & $16(80 \%)$ & $20(23.8 \%)$ & & \\
\hline Cryptosporidium parvum & $1(14 \%)$ & $7(86 \%)$ & $8(9.5 \%)$ & & \\
\hline Cyclospora caytanensis & 0 & $2(100 \%)$ & $2(2.4 \%)$ & & \\
\hline Total number & $23(27.4 \%)$ & $61(72.6 \%)$ & $84(100 \%)$ & & \\
\hline
\end{tabular}

Parasitic infections: 58(57.4\%) in IBD pa- C. caytanensis as (27)27\%, (14)14\%, (10) tients \& 26(22\%) in IBS, with a significant difference. Parasites were E. histolytica/dispar, G. lamblia, B. hominis, C. parvum and $10 \%$, (6) $6 \%$ and $(1) 1 \%$ in IBD patients, (10) $8 \%,(6) 5 \%,(7) 6 \%,(2) 2 \%$ and (1) $1 \%$ in IBS ones respectively.

Table 3: Hematological parameters in relation to fecal calprotectin antibody levels in IBD and IBS cases:

\begin{tabular}{|l|c|c|c|c|}
\hline \multirow{2}{*}{ Variables } & \multicolumn{2}{|c|}{ Fecal calprotectin antibody } & \multirow{2}{*}{$\begin{array}{c}\text { Statistical } \\
\text { analysis }\end{array}$} & \multirow{2}{*}{ P-value } \\
\cline { 2 - 3 } & +ve & -ve & & \\
\hline IBD & $57(83 \%)$ & $44(29 \%)$ & $X^{2} 53.98$ & $0.000^{*}$ \\
IBS & $12(17 \%)$ & $106(71 \%)$ & & \\
\hline Anemia +ve & $43(62 \%)$ & $33(22 \%)$ & $X^{2} 33.9$ & $0.000^{*}$ \\
-ve & $26(38 \%)$ & $117(78 \%)$ & & \\
\hline $\mathrm{Hb}(\mathrm{gm} / \mathrm{dl}) \quad \mathrm{M} \pm$ SD & $10.63 \pm 0.73$ & $11.42 \pm 1.8$ & t-test 1.202 & 0.128 \\
\hline Mean total leucocytes & 11463 & 8270 & t-test 3.82 & $0.002^{*}$ \\
Neutrophil $(\%)$ & $72.9 \%$ & $61.3 \%$ & & \\
\hline
\end{tabular}

*Significant differences at P-value $<0.05$

Calprotectin antibody levels were positive $(\geq 50 \mathrm{ng} / \mathrm{ml}$ ) in 69 cases. Highest proportion of positive was in IBD patients $57(83 \%)$ and $12(17 \%)$ in IBS ones with a significant dif- 
ference. Among calprotectin positive cases, $62 \%$ were anemic with $\mathrm{Hb}(10.63 \pm 0.73)$ and mean total leucocytes and neutrophil percentage $11463, \& 72.9 \%$ respectively with a significant difference.

Among 84 parasitic infected cases, calprotectin levels were positive in 23(27.4\%): $E$ histolytica/dispar 15(40.5\%), G. lamblia 4 (20\%), B. hominis 3(17.6\%), and C. parvum $1(14 \%)$.

\section{Discussion}

Intestinal parasitosis has a strong effect on gastrointestinal tract especially by an invasive parasitic agent (Ali et al, 2018). Lower intestinal symptoms, as chronic abdominal pain or discomfort with diarrhea or constipation, are common symptoms in different pathological and functional bowel disorders including inflammatory bowel disease (IBD) and irritable bowel syndrome (IBS) respectively (Walsham and Sherwood, 2016).

Calprotectin is a small calcium-binding protein among the S100 family of zinc-binding proteins, mainly released from degranulated neutrophils but to lesser extent from other phagocytic cells as monocytes and macrophages during inflammation (Hanauer, 2017). In active intestinal inflammation, leakage of neutrophils and calprotectin pass into the lumen and excrete in feces. So, the fecal calprotectin concentration reflects the number of participating neutrophils in this inflammation and depends on the severity of the intestinal inflammation (Walsham and Sherwood, 2016).

Fecal calprotectin is used as a good indicator of intestinal mucosal inflammation. It is easy, rapid, and non-invasive laboratory test along with simple microscopic examination of stool, can be used as an indicator of intestinal inflammation and to differentiate the IBD from the IBS (Duman et al, 2015).

The aim of this study is to determine the prevalence of intestinal protozoa among patients with IBD and IBS and to evaluate the degree of injuries caused by these protozoa on the gastrointestinal tract by measuring the fecal calprotectin (FC) level.
In this study, 219 cases were 101 IBD cases and 118 IBS cases, 116 (53\%) males and $103(47 \%)$ females. Male patients represented the highest proportion of IBD patients $(60 \%)$, while females represented the highest proportion of IBS $(53.4 \%)$ with a significant difference between. The results agreed with Ali et al. (2018) and Morgan et al. (2012) who reported that males were more affected by IBD but females were more affected by IBS. In the present study, the most affected age group with IBD was from 15 to 35 years $(47.5 \%)$, while the most affected IBS age group was from 36 to 50 (44\%) without significant difference. These results more or less agreed with Walsham and Sherwood (2016) who reported that the typical age of IBD was between 15 years and 30 years, but up to $20 \%$ during childhood, and the most common age of IBS was between 20 years and 30 years. In the present study, IBD \& IBS (126) cases were from rural areas without significant difference.

In the present study, $84(38.4 \%)$ cases were infected by different parasites. Parasites were detected in 58(57.4\%) IBD patients and in $26(22 \%)$ IBS patients with a significant difference. The protozoan parasites detected were Entamoeba histolytica/dispar, Giardia lamblia, Blastocystis hominis, Cryptosporidium parvum and Cyclospora caytanensis. Prevalence among IBD were (27) $27 \%$, (14)14\%, (10)10\%, (6)6\%, and (1)1\% while among IBS were $(10) 8 \%,(6) 5 \%$, (7) $6 \%,(2) 2 \%$ and (1) $1 \%$ respectively.

In the present study, E. histolytica/dispar was the most prevalent protozoa, 37 (44\%), more prevalent in IBD (27\%) than IBS $(8 \%)$ cases. No doubt, the invasive parasite could penetrate intestinal mucosa causing marked inflammation and flask shaped ulcers. This agreed with Salman et al, (2017) who found amoebiasis represented $43.21 \%$. Nevertheless, the present data were higher than those recorded as 5.11\%, (Morsy et al, 1991), 4.9\% (Hamzy et al, 2003), 21.2\% (Al-Nak kas et al, 2004), 4.57\% (Ismaiel, 2011) and 16\% (Babic et al, 2016). 
Salman et al. (2016) reported that the liquid diarrhea picture in acute cases mimic that of IBS, also, the color and even the odor of the positive Giardia stool samples were the same. While in chronic giardiasis, clinical picture resemble IBD mainly epigastric pain and the other sequels. In this study, $G$. lamblia infection was in 20 cases (23.8\%). It was more prevalent in IBD (14\%) than IBS (5\%). Salman et al. (2017) found G. lamblia $(17.66 \%)$ cases more among IBD patients than IBS ones. Also, the present results agreed with Grazioli et al. (2006), who found that $G$. lamblia infections occurred in $6.5 \%$ of people with IBS symptoms. Also, Dizdar et al. (2010) found increased post-infectious bowel dysfunction, IBS patients after Giardia infection. But, the present results were higher than that reported by Morgan et al. (2012) and Bujanda et al. (2002) 3.0\% and $2.7 \%$ respectively among IBS cases.

In the present study, $B$. hominis infection was in $20.2 \%, 10 \%$ in IBD patients and $6 \%$ in IBS ones. This result agreed with Cekin $e t$ al, (2012) who reported higher Blastocystis infection among IBD patients $(8.35 \%)$ compared to those with IBS (5.82\%). These results were higher than that of Salman et al. (2017) who detected (11.65\%) of cases more in IBD patients than IBS ones. But, Hammood et al. (2016) found higher rate of $B$. hominis $(37.75 \%)$ infection. The difference might be due to higher number of patients (608) examined that was higher among IBD patients than IBS ones. Others reported a moderately strong association between $B$. hominis infection and symptomatic IBS that varied among the geographic areas (Grazioli et al, 2006; Yakoob et al, 2010; Coyle et al, 2012).

In the present study, $C$. parvum infection rate was $9.5 \%$, affected $6 \%$ of IBD patientss and $2 \%$ of IBS ones. These results disagreed with Jadallah et al. (2017) who detect $C$. parvum in $12.8 \%$ of IBS patients. Also, Vadlamudi et al. (2013) detected $C$. parvum infection in $18 \%$ of the IBD patients and accounted $4.6 \%$ of all IBD relapses.
Khaldi et al. (2009) reported that cryptosporidiosis in suckling rats caused jejunal hypersensitivity to distension associated with accumulation of activated mast cells at $50 \mathrm{~d}$ post-infection. This showed that cryptosporidiosis is diarrhea-predominant. IBS cases have a marked increase in mast cells number and elevated tryptase concentrations in jejunal mucosa (Guilarte et al, 2007).

In the present study, $C$. caytanensis was $2.4 \%$ of infected cases. Only $1 \%$ of IBD and IBS cases were infected. Cyclosporiasis gave symptoms resembling celiac disease and irritable bowel syndrome (Karanja et al, 2007)

Kopylov et al. (2016) reported that FC antibody levels normal (10-50ng/ ml) and levels above $50 \mathrm{ng} / \mathrm{ml}$ denoted damage in GIT indicating endoscopy intervention.

In the present study, fecal calprotectin antibody levels were positive in 69 cases. The highest proportion was among IBD patients $57(83 \%)$ while only $12(17 \%)$ among IBS ones with a significant difference. These results agreed with Hanauer (2017) who reported that $99 \%$ of patients with active IBD gave elevated fecal calprotectin levels while, $15 \%$ to $20 \%$ of IBS patients gave mild levels. Also, Tursi et al. (2011) and Sydora et al. (2012) reported that fecal calprotectin levels among IBS patients were much lower than in patients with IBD, without significant different from healthy individuals.

In the present study, calprotectin positive cases, $62 \%$ were anemic, $\mathrm{Hb}(10.63 \pm 0.73)$ with mean total leucocytes and neutrophil\% were elevated $11463,72.9 \%$ respectively with a significant difference between calprotectin positive and negative cases. This data agreed with Salman et al (2017) who re- prted high total WBC count and neutrophilia among patients with elevated fecal calprotectin due to acute $E$. histolytica infection. Also, Ali et al. (2018) reported decreased mean $\mathrm{Hb}$ level and neutrophilia among patients with elevated fecal calprotectin level but decreased mean total white blood cells due to parasitic infection. 
In the present study, among 84 parasitic infected cases, calprotectin levels were positive in $23(27.4 \%)$ patients stool samples with E. histolytica/dispar 15(40.5\%), G. lamblia 4(20\%), B. hominis 3(17.6\%), C. parvum 1(14\%). These results agreed with Salman et al.(2017) who reported elevated fecal calprotectin in $(41.75 \%)$ of E. histolyti$c a$ infected cases followed by $(21.27 \%)$ of G. lamblia and $(3.22 \%)$ of B. hominis infected cases.. Also, the results agreed withGol et al. (2018) and Hanevik et al. (2007) who noted that some parasitic diseases as $G$. $d u$ odenalis increased the level of fecal calprotectin among patients with IBD. Besides, increased in fecal calprotectin was due to $S c$ histosoma mansoni (Bustinduy et al, 2013) and Dientamoeba fragilis (Munasinghe et al, 2013).

\section{Conclusion}

Undoubtedly, intestinal protozoa infections are more prevalent among patients with IBD when compared to those with IBS. The degree of damages in GIT due to protozoa infections was clarified efficiently by measuring $\mathrm{FC}$ as a dependent test.

\section{References}

Adegbola, RA, Demba, E, Deveer, G, Todd, F, 1994: Cryptosporidium infection in Gambian children less than 5 years of age. Am. J. Trop. Med. Hyg. 97:103-7.

Adisakwattana, P, Nuamtanong, S, Kusolsuk ,T, Chairoj ,M, Yenchitsomanas, PT, et al, 2013: Non-encapsulated Trichinella spp., T. papuae, diminishes severity of DSS-induced colitis in mice. Asian Pac. J Aller. Immunol. 31, 2:10614.

Ali, OS, Mohammad, SA, Salman, YJ, 2018: Relationship between Entamoeba histolytica and Fecal Calprotectin. Egypt. J. Med.Microbiol. 27, 2:49-56.

Al-Nakkas, E, Al-Mutar, EM, Shweiki, HM, Sharm, PN, Rihan, S, 2004: Parasitic infection in Kuwait. A study based on primary care center. Med. East. J. Fam. Med. 3:7-12.

Andersen, V, Olsen, A, Carbonnel, F, Tjønneland, A, Vogel, U, 2012: Diet and risk of inflammatory bowel disease. Digest. Liver Dis. 44, 3:185-94.

Babić, E, Bevanda, M, Mimica, M, Karin, M,
Volarić, M, et al, 2016: Prevalence of amebiasis in inflammatory bowel disease in University Clinical Hospital Mostar. Springer-Plus. 5, 1: 1586 doi: 10.1186/s40064-016-3261-7

Baumgart, DC, Carding, SR, 2007: Inflammatory bowel disease: cause and immunobiology. Lancet 369, 9573:1627-40.

Borgaonkar, MR, Ford, DC, Marshall, JK, Churchill, E, Collins, SM, 2006: The incidence of irritable bowel syndrome among community subjects with previous acute enteric infection. Dig. Dis. Sci. 51:1026-32.

Bujanda, L, Guti'errez-Stampa, MA, Caballeros, C H, Alkiza, ME, 2002: Gastrointestinal disorders in Guatemala and their relation with parasitic infections. Ana. de Med. Int..19, 4:17982.

Bustinduy, AL, Sousa-Figueiredo, JC, Adriko, M, et al, 2013: Fecal occult blood and fecal calprotectin as point-of care markers of intestinal morbidity in Ugandan children with Schistosoma mansoni infection. PLoS Negl Trop Dis. 7, 11:25-42.

Cekin, AH, Cekin, Y, Adakan, Y, Tasdemir, E, Koclar, FG, et al, 2012: Blastocystosis in patients with gastrointestinal symptoms: a casecontrol study. BMC Gastroenterol.12:122.

Cheesbrough, M, 1987: Medical Laboratory Manual for Tropical Countries: ELBS Tropical Health Technology Butterworth.

Cheesbrough, M, 2009: District Laboratory Practice in Tropical Countries: vol.1. New York, Cambridge University Press.

Coyle, CM, Varughese, J, Weiss, LM, Tanowitz, HB, 2012: Blastocystis: to treat or not to treat. Clin. Infect. Dis. 54, 1:105-10.

Dizdar, V, Spiller, R, Singh, G, Hanevik, K, Gilja, O, et al, 2010: Relative importance of abnormalities of CCK and 5-HT (serotonin) in Giardia-induced post-infectious irritable bowel syndrome and functional dyspepsia. Aliment. Pharmacol. Ther. 31:883-91.

Dogruman, AF, Simsek, Z, Boorom, K, Ekici, E, Sahin, M, et al, 2010: Comparison of methods for detection of Blastocystis infection in routinely submitted stool samples, and also in IBS/IBD Patients in Ankara, Turkey. PLoS One; 5:e15484.

Drenaggi, D, Cirioni, O, Giacometti, A, Fiorentini, A, Scalise, G, 1998: Cyclosporiasis in a traveler returning from South America. J Travel Med. 5:153-5. 
Duman, M, Gencpinar, P, Biçmen, M, Arslan, N, Özden, Ö, et al, 2015: Fecal calprotectin: can be used to distinguish between bacterial and viral gastroenteritis in children? Am. J. Emerg. Med. 33, 10:1436-9.

Eberhard, ML, Nace, EK, Freeman, AR, Streit, TG, da Silva, AJ, et al, 1999: Cyclospora cayetanensis infections in Haiti: a common occurrence in the absence of watery diarrhea. Am J Trop Med Hyg. 60:584-6.

Engsbro, AL, Stensvold, CR, Vedel Nielsen, H, Bytzer, P, 2014: Prevalence, incidence, and risk factors of intestinal parasites in Danish primary care patients with irritable bowel syndrome. Scand. J. Infect. Dis. 46: 204-9.

Fengming, Y, Jianbing, W, 2014: Biomarkers of inflammatory bowel disease. Dis. Markers 710915.

Fletcher, SM, Stark, D, Harkness, J, Ellis, J, 2012: Enteric protozoa in the developed world: a public health perspective. Clin. Microbiol. Rev. 25:420-49.

Foell, D, Wittkowski, H, Roth, J, 2009: Monitoring disease activity by stool analyses: from occult blood to molecular markers of intestinal inflammation and damage. Gut 58:859-68.

Gol, SM, Mirjalali, H, Aghdaei, HA, Zali, MR, 2018: Can Giardia infection impair the diagnostic level of fecal calprotectin in patients with inflammatory bowel disease? A case report. Iranian J, Parasitol. 13,3 :505-509.

Hanevik, K, Hausken, T, Morken, MH, et al, 2007: Persisting symptoms and duodenal inflammation related to Giardia duodenalis infection. J. Infect.55, 6:524-30.

Grazioli, B, Matera, G, Laratta, C, 2006: $G i$ ardia lamblia infection in patients with irritable bowel syndrome and dyspepsia: a prospective study. Wld. J. Gastroenterol. 12, 12:1941-4.

Griffiths, JK, 1998: Human cryptosporidiosis: epidemiology, transmission, clinical disease, treatment, and diagnosis. Adv. Parasitol. 40, 37:85-9.

Gwee, KA, 2005: Irritable bowel syndrome in developing countries a disorder of civilization or colonization? Neurogastroenterol. Motil.17, 3: 317-24.

Hammood, AM, Salman, YJ, Ahmed, BA, 2016: Possible association between Blastocystis hominis and bowel disorders among Iraqi $\mathrm{Pa}-$ tients in Kirkuk Province. Int. J. Curr. Res. Acad. Rev. 4, 7:50-6.

Hamzy, M, Dabboussi,F, Al-Ali, K, Ourabi,
L, 2003: Prevalence of intestinal parasites in Northern Lebanon. East. Medite. Hlth. J. 10, 3:343-6.

Hanauer, SB, 2017: The use of fecal calprotectin in inflammatory bowel disease. Gastroenterol. Hepatol. 13, 1:53-56.

Hansen, LH, Lund, C, 1998: Amebiasis-a differential diagnosis from inflammatory bowel disease. Ugeskr. Laeger. 160:5514-5.

Holtman, GA, Lisman-van Leeuwen, Y, Reitsma, JB, Berger, MY, 2016: Non-invasive tests for inflammatory bowel disease: a metaanalysis. Pediatrics 137, 1:1-11.

Ismaiel, MT, 2011: Detection of intestinal parasites among primary shool children in HamaSyria. J. Med. Lab. Diag. 10:1-9.

Karanja, RM, Gatei, W, Wamae, N, 2007: Cyclosporiasis: an emerging public health concern around the world and in Africa. Afr. Hlth. Sci. 7, 2:62-7.

Kaser, A, Zeissig, S, Blumberg, RS, 2010: Inflammatory bowel disease. Ann. Rev Immunol. 28:573-621.

Khaldi, S, Gargala, G, Le Goff, L, Parey, S, Francois, A, et al, 2009: Cryptosporidium parvum isolate-dependent postinfectious jejunal hypersensitivity and mast cell accumulation in an immunocompetent rat model. Infect Immun.77:5163-9.

Jadallah, KA, Nimri, LF, Ghanem, RA, 2017: Protozoan parasites in irritable bowel syndrome: A case control study. Wld. J. Gastrointest. Pharmacol.Ther. 8, 4:201-7.

Kim, SC, Ferry, GD, 2004: Inflammatory bowel diseases in pediatric and adolescent patients: clinical, therapeutic, and psychosocial considerations. Gastroenterology.126, 6:1550-60.

Kopylov, U, Yung, DE, Engel, T, Avni, T, Battat, R, et al, 2016: Fecal calprotectin for screening of patients with suspected inflammatory bowel disease: diagnostic meta-analysis Eur. J. Gastroenterol. Hepatol. 28, 10:1137-44

Lau, YL, Anthony, C, Fakhrurrazi, SA, Ibrahim, J, Ithoi, I, et al, 2013: Realtime PCR assay in differentiating Entamoeba histolytica, Entamoeba dispar, and Entamoeba moshkovskii infections in Orang Asli settlements in Malaysia. Parasit. Vectors 6:250-2.

Lehmann, FS, Burri, E, Beglinger, C, 2015: The role and utility of faecal markers in inflammatory bowel disease. Thera. Adv. Gastroenterol. 8, 1:23-6.

Lennard-Jones, J, 1989: Classification of infl- 
ammatory bowel disease. Scand. J. Gastroenterol. 24:2-6.

Longstreth, GF, Thompson, WG, Chey, WD, Houghton, LA, Mearin, F, et al, 2006: Functional bowel disorders. Gastroenterology 131, 2: 688-70.

Maloy, KJ, Powrie, F, 2011: Intestinal homeostasis and its breakdown in inflammatory bowel disease. Nature 474, 7351:298-306.

Mansfield, LS, Gajadhar, AA, 2004: Cyclospora cayetanensis, a food- and waterborne coccidian parasite. Vet. Parasitol. 126:73-90.

Mertz, HR, 2003: Irritable bowel syndrome. New Engl. J. Med. 349, 22:2136-46.

Morgan, DR, Benshoff, M, C'aceres, M, Becker-Dreps, S, Cortes, L, et al, 2012: Irritable bowel syndrome and gastrointestinal parasite infection in a developing nation environment. Gastroenterol. Res. Pract. 2012:343812

Morsy, TA, Farrag, AM, Sabry, A, Salama, MM, Arafa, MA, 1991: Ecto and endo-parasites in low primary schools in Qualyob City, Egypt. J. Egypt. Soc. Parasitol. 21, 2:391-401.

Munasinghe, VS, Vella, NG, Ellis, JT, Windsor, PA, Stark, D, 2013: Cyst formation and fecal-oral transmission of Dientamoeba fragilis the missing link in the life cycle of an emerging pathogen. Int. J. Parasitol. 43, 11:879-83.

Ng, SC, Shi, HY, Hamidi, N, Underwood, FE, Tang, W, 2018: Worldwide incidence and prevalence of inflammatory bowel disease in the 21 st century: a systematic review of populationbased studies. Lancet.390, 10114:2769-78.

Parray, FQ, Wani, ML, Malik, AA, Wani, S N, Bijli, AH, et al, 2012: Ulcerative colitis: A challenge to surgeons. Int. J. Preven. Med. 3:749.

Ponder, A, Long, MD, 2013: A clinical review of recent findings in the epidemiology of inflammatory bowel disease. Clin. Epidemiol. 5: 237-47.

Quail, MA, Russell, RK, Van Limbergen, JE, et al, 2009: Fecal calprotectin complements routine laboratory investigations in diagnosing childhood inflammatory bowel disease. Inflamm. Bowel Dis. 15, 5:756 -9.

Salman, YJ, Al-Taee, AA, Mohammad, AA, 2016: Role the employee of some biological stains in detecting Giardia lamblia among Internal Iraqi Displaced Peoples in Kirkuk Province. Int. J. Curr. Microbiol. App. Sci. 5, 3:705-18.

Salman,YJ, Ali, CA, Abdul Razaq, AA, 2017: Fecal calprotectin among patients infected with some protozoan infections, Int. J. Curr. Microbiol. App. Sci. 6, 6:3258-74.

Sherwood, RA, 2012: Fecal markers of gastrointestinal inflammation. J. Clin. Pathol. 65:9815 .

Shields, JM, Olso, BH, 2003: Cyclospora cayetanensis: a review of an emerging parasitic coccidian. Int. J. Parasitol. 33:371-91.

Stark, D, van Hal, S, Marriott, D, Ellis, J, Harkness, J, 2007: Irritable bowel syndrome: a review on the role of intestinal protozoa and the importance of their detection and diagnosis. Int. J. Parasitol. 37, 1:11-20.

Thabane, M, Kottachchi, DT, Marshall, JK, 2007 : Systematic review and meta-analysis: the incidence and prognosis of postinfectious irritable bowel syndrome. Alim. Pharmacol.Therape. 26, 4: 535-44.

Sydora, MJ, Sydora, BC, Fedorak, RN, 2012: Validation of a point-of-care desk top device to quantitate fecal calprotectin and distinguish inflammatory bowel disease from irritable bowel syndrome. J. Crohn's Colitis 6, 2:207-14.

Tursi, A, Elisei, W, Giorgetti, G, Aiello, F, Brandimarte, G, 2011: Role of fecal calprotectin in the diagnosis and treatment of segmental colitis associated with diverticulosis. Minerva Gastroenterol. Dietol. 57, 3:247-55.

Vadlamudi, N, Maclin, J, Dimmitt, RA, Thame, KA, 2013: Cryptosporidial infection in children with inflammatory bowel disease. J. Crohn's Colitis 7, 9:337-43.

Varea, M, Clavel, A, Doiz, O, Castillo, FJ, Rubio, MC, et al, 1998: Fuchsin fluorescence and autofluorescence in Cryptosporidium, Isospora and Cyclospora oocysts. Int. J. Parasitol. 28:1881-3.

Walsham, NE, Sherwood, RA, 2016: Fecal calprotectin in inflammatory bowel disease. Clin. Exp. Gastroenterol. 9:21-9.

Wang, GF, Ren, JA, Liu, S, Chen, J, Gu, GS, et al, 2012: Clinical characteristics of nonperianal fistulating Crohn's disease in China: a single-center experience of 184 cases. China Med. J. 125,14: 2405-10.

Wensaas, KA, Langeland, N, Hanevik, K, Mørch, K, Eide, GE, et al, 2012: Irritable bowel syndrome and chronic fatigue 3 years after acute giardiasis: historic cohort study. Gut 61 , 2:214-9.

Wilson, S, Roberts, L, Roalfe, A, Bridge, P, Singh, S, 2004: Prevalence of irritable bowel syndrome: a community survey. Br. J. Gen. Pract. 
54, 504:495-502.

Wolska-Kusnierz, B, Bajer, A, Caccio, S, Heropolitanska, Pliszka, E, et al, 2007: Cryptosporidium infection in patients with primary immunodeficiencies. J. Pediatr Gastroenterol. Nutr. 45:458-64.
Yakoob, J, Jafri, W, Beg, MA, et al, 2010: Irritable bowel syndrome: is it associated with genotypes of Blastocystis hominis. Parasitol. Res. 106, 5:1033-8.

\section{Explanation of figures}

Fig. 1: Intestinal parasites among IBD patients.

Fig. 2: Intestinal parasites among IBS patients.
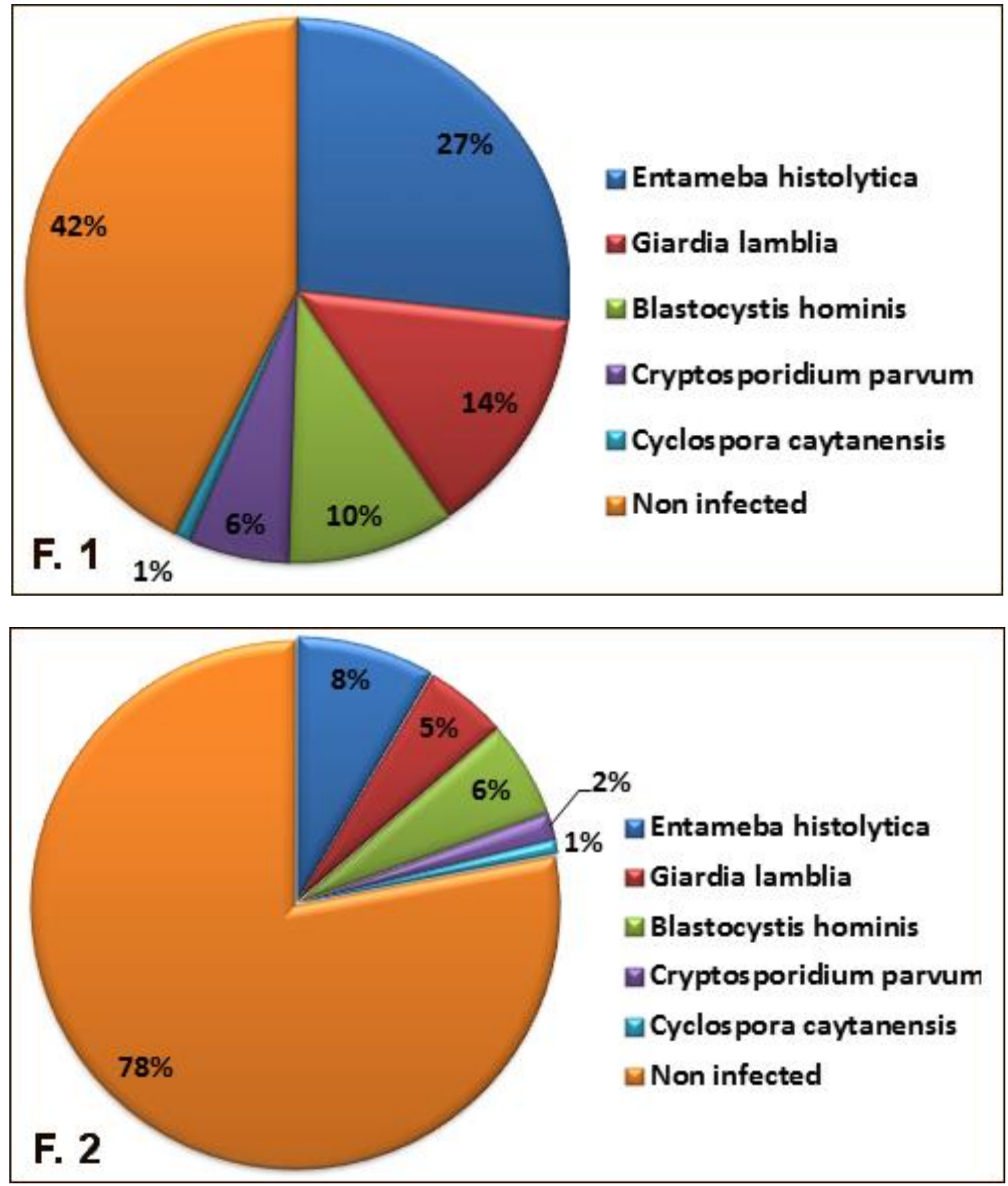